\title{
A subversão consciente do caráter não infantilizado da criança em Machado de
}

\author{
Assis \\ The conscious subversion of the not infantile character of the child in Machado \\ de Assis
}

\author{
Zênia Regina dos Santos Barbosa*, Fernando Filgueira Barbosa Júnior**, Mona Lisa Bezerra Teixeira** \\ * FPCEUC, ** PPGL/UERN
}

\begin{abstract}
Resumo
Ao tocar em aspectos da conduta humana, Machado de Assis sinaliza em sua obra, caminhos para compreendermos, através da Literatura, os comportamentos sociais que ainda hoje manifestam-se propícios a estudos mais densos. Destes aspectos, a infância é apresentada sob uma perspectiva desvelada de representar, através da criança, as sensações do mundo adulto e seus problemas sociais. Selecionamos para essa análise recortes do "Conto de Escola" da coletânea "Várias Histórias" (2003), onde através da subversão consciente do caráter da personagem, conduziremos um olhar historicista e sociológico norteando o recôndito irônico machadiano. Palavras-chave: Machado de Assis. Infância. Conto de Escola.
\end{abstract}

\begin{abstract}
Talking about the human conduct, Machado de Assis shows in his work, ways to understand, trough Literature, the social behaviors that still today are more likely to study. Of these aspects, the childhood is presented under an unveiled perspective by represent, trough the child, the sensations of the adult world and his socials problems. We selected for this analysis excerpts by "Conto de Escola" from the collection "Várias Histórias" (2003), where trough character's conscious subversion character, we going to the historicist and sociologist vision in the machadiano's ironic recess.
\end{abstract}

Keywords: Machado de Assis. Childhood. Conto de Escola.

\section{Considerações iniciais}

"Conto de Escola" (2003) nos relata a história de uma infância sob uma perspectiva não infantilizada, onde Machado de Assis por meio de uma unidade temática ( $c f$. Cortázar, 1974) revela aspectos para, através do narrador - Pilar ou "Seu Pilar", conduzirmos nossa análise de modo não panfletário. Segundo Gledson (2006, p. 92), essa é uma narrativa de "realismo vívido e autêntico de moral explícita", justamente por desmascarar, de forma irônica - o que é muito característico em Machado de Assis, aspectos corruptos da conduta humana; tudo de maneira velada, contado por uma criança.

Como o próprio nome sugestiona, a narrativa se passa em uma escola - espaço de aprendizagem. Faz-se saber que em um dia convencional de aula, Pilar recebe a tentadora proposta de um colega de sala, Raimundo - filho do professor, a receber uma moeda em troca de lhe fazer a tarefa. Mais tarde, a peraltice é delatada por outro colega de sala, o Policarpo, o que rende aos meninos uma simbólica punição.

Para melhor ilustrarmos esse pensamento, optamos, para fins metodológicos, dividir os aspectos observados neste trabalho em algumas categorias de análise, tais como: o estranhamento; o tempo cronológico; a subversão consciente do caráter da personagem; a inoperância do homem livre; as alegorias; o espaço onírico e, é claro, a infância.

A infância na perspectiva Machadiana e os recónditos históricos e ironicos em conto de escola.

$\mathrm{O}$ primeiro aspecto da infância machadiana que nos chama a atenção no conto é o estranhamento. Em uma perspectiva todoroviana, esse estranhamento poderia ser lido como algo fantasmagórico, no entanto, no plano do realismo fantástico, Machado faz alusão à normalidade. Vejamos:

Há um narrador criança com duas possibilidades de espaço: o morro de S. Diego e o campo de Sant'Ana, no entanto, ele escolhe a escola, o que de algum modo já rompe com a normalidade dessa criança; haja vista que, convencionalmente, a maioria das crianças não deixaria de brincar no parque para ir à escola. Contudo, esse pensamento se atenua se considerarmos que há um fator que impulsiona Pilar a ir para a escola: o castigo que havia recebido dias antes. (Assis, 2003, p. 102).

A segunda categoria de análise diz respeito ao tempo cronológico do conto, o que já antecipa o caráter histórico que recorreremos mais adiante. A história se passa em maio de 1840, e:

A referência a maio de 1840 é cuidadosamente escolhida. A Regência estava acabando, em um sentido muito específico: esse foi o mês em que uma seção do Partido Liberal propôs pela primeira vez a antecipação da Maioridade de d. Pedro II, que faria 18 anos somente em 1843, mas que foi de fato proclamado maior de idade quando tinha catorze anos, em 23 de julho de 1840. (Gledson, 2006, p. 93).

Logo, há uma inevitável associação irônica entre Pilar e D. Pedro II, que se afunilará no decorrer do conto, sobretudo ao falarmos das alegorias - ambos - 
personagem real e personagem fictício numa perspectiva sociológica e histórica.

Em relação à subversão consciente do caráter da personagem, esta se dá quando Pilar vê a moeda (propina) pela primeira vez e tem consciência que poderia escolher não fazer o "serviço sujo" oferecido por seu colega Raimundo, contudo, ele "não era um menino de virtudes" (Assis, 2003, p. 102) e assim aceita fazê-lo. Ou seja, ele entra para o mundo da corrupção consciente disso e permanece nesse plano até o fim da narrativa.

Diante dessa fragilidade do caráter humano, outro aspecto que se revela enquanto categoria de nossa análise é a inoperância do homem livre ${ }^{1}$. Ela se dá, no conto, por meio da personagem Policarpo, vejamos:

Policarpo tinha decerto algum partido, mas nunca pude averiguar esse ponto. $\mathrm{O}$ pior que ele podia ter para nós era a palmatória. E essa lá estava, pendurada do portal da janela, à direita, com os seus cinco olhos do diabo. (Assis, 2003, p. 104).

A falta de valor social do professor Policarpo acarretalhe uma espécie de recalcamento ou frustração social; o que revela-se pertinentemente atual se considerarmos que ele está inserido em uma das classes sociais menos favorecidas da atualidade. Este "homem livre", ainda nas palavras de Paulo Mercadante, se descortina como uma pessoa "sem validade pública", valendo-se de seu caráter doutrinador para a rígida educação das crianças. Segundo John Gledson:

O silêncio frustrado de Policarpo, reduzido a grunhidos e gestos, é o resultado direto de sua falta de "validade pública". Isso não quer dizer, obviamente, que Policarpo é "bom demais para este mundo"; não é isso, evidentemente. É, sem dúvida, de certa maneira trágico que ele somente possa descarregar sua raiva sobre um símbolo que é a moeda, ou sobre seu próprio filho, mas "bufando de raiva" trás de seus "três ou quatro" jornais, ele também fica mais ridículo, e uma figura muito típica de Machado: uma pessoa para quem a política é um fim em si mesmo, um entorpecente ou, para uma metáfora menos banal, uma coceira que deve ser continuamente coçada. (Gledson, 2006, p. 98).

Chegamos então nas alegorias, conforme antecipamos, são os elementos que Machado introjeta no conto para satirizar a própria História e, aos poucos, vão nos dando pistas de onde ele realmente quer chegar e a quem, de fato, pretende atingir. Algumas delas são manifestadas textualmente de maneira bem direta, como o "Trono de Jerusalém" (Assis, 2003, p. 108) que está disposto na Bíblia (Almeida, 2008), nos livros de: Reis $(2,12)$; Reis (10,18); Crônicas (29, 22-23); e em Apocalipse (4, 2-3). Esse trono do qual a personagem se assentaria por seu estado de glória é uma associação direta ao trono do Rei Davi e também de D. Pedro, uma vez que a riqueza da monarquia muito se aproxima da riqueza bíblica, e porque não literária, do Rei Salomão.

Em vista disso, Gledson (2006, p. 99) questiona "será que não poderia ter outras implicações, em um contexto no qual uma criança está prestes a assumir o trono no
Brasil?" As alegorias que seguem no conto, continuam a descortinar esse pensamento, sobretudo quando evoca a "marcha dos fuzileiros" e o "tambor" (Assis, 2003, p. 109) como representação social republicana.

Há ainda, nesse sentido, a canção que a personagem ouve tocar na rua e entra na marcha: "Rato na Casaca" (Assis 2003, p. 109). De acordo com Gledson (2006, p. 101) provavelmente não há uma canção com esse nome, mas como nada, nenhum sintagma nominal está posto por obra do acaso em Machado de Assis, é pertinente analisar a simbologia do Rato e da Casaca. Sendo a casaca uma espécie de indumentária imperial, e o rato associado ao animal peçonhento e ladrão, desmerecendo dessa maneira a indumentária.

A "casaca" é uma vestimenta sempre associada com políticos do Império; a associação com o rato parece implicar pouco respeito por eles, se não implica corrupção efetiva, ou traição: mesmo hoje em dia "virar a casaca" é uma expressão comum para descrever para descrever um político que muda de partido, normalmente por motivos desonestos. (Gledson, 2006, p. 101)

Em vista dessa perspectiva, passemos, porém a analisar a infância, propriamente dita, da personagem/ narrador do conto. A princípio percebamos o espaço onírico ao qual se inclui, desse modo, um plano de "não consciência" de todos os fatos que estão sendo descortinados; a metáfora e a ironia assumem esse papel nos escritos de Machado de Assis, uma vez que:

As histórias de Machado costumam inserir detalhes políticos e históricos, como os que analisamos aqui em referências oblíquas [...] isso não é somente a obscuridade pela obscuridade, mas deriva de uma situação complexa, em que a repressão tem um papel mais ou menos disfarçado, mas sobretudo, em que é difícil para as opiniões liberais. (Gledson, 2006, p. 101) $\mathrm{O}$ sonho que Pilar tem na noite mal dormida - sem a moeda, cujas faculdades oníricas lhe permitem acreditar que, no dia seguinte, a encontraria na rua e a recuperaria sem nenhum pudor ( $c f$. Assis, 2003, p. 108), se apresenta na curta narrativa como uma espécie de input à personagem. Ansiando tanto quanto ou mais o Tio Patinhas desejaria sua moeda, Pilar se constitui nesse plano onírico da inconsciência de acordo com Gledson (2006, p. 101) como um "narrador criança 'inocente', que não pode ver a verdade embora possa ver seus indícios." Assim, nos tornamos - enquanto leitores, tão "inocentes" como o narrador.

De acordo com Gaston Bachelard (1988, p. 60), “[...] o repouso da noite não nos pertence, [...] o sono abre em nós um albergue de fantasmas." Considerando esse pensamento, haveremos de considerar, e por isso tornarse-á pertinente a leitura, de que o fator que impulsiona Pilar - o sonho - a reencontrar "sua moeda" o conduz, no dia seguinte, de maneira simbólica, para todas as alegorias políticas e sociológicas que aqui expusemos; e, embora esteja a personagem revestida dessa inocência

\footnotetext{
${ }^{1}$ Expressão capturada da citação de Paulo Mercadante, In Gledson, John. (2006). Por um novo Machado de Assis. São Paulo: Companhia das Letras.
} 
irônica machadiana, ela tem consciência plena do que deseja o tempo inteiro.

Novamente procuramos aporte em Bachelard (1988, p. 102) para justificar a pertinência da infância nessa "denúncia/ crítica" que Machado tão genialmente faz em Conto de Escola. Ao dizer que a infância é naturalmente fabulosa, o poeta considera que "o núcleo da infância permanece na psique humana", talvez por isso Machado tenha escolhido esse narrador criança, pois sendo ele, "inocente" à toda conjuntura política e social de 1984, ele a representa quando corrompe sua moral aceitando fazer o serviço sujo.

\section{Considerações finais}

A subversão consciente talvez soe, inclusive foneticamente, como um tema um tanto forte para aplicar a uma criança de colégio primário, ainda que se trate de uma personagem de ficção. Entretanto, se forte nos é hoje, bem mais impactante tivera sido em 1840 aliado à conjuntura política do Brasil no fim da Regência. E é nesse momento que a prosa ficcional e a vida real se entrecruzam para resignificar os protótipos de vida e sociedade.

Todos os elementos do conto "intencionalmente calculados" fazem de "Conto de Escola" uma lição de moral sobre os aspectos que norteiam a conduta humana, sobretudo quando é lido pela ótica social e política conforme nos apresenta John Gledson em seus escritos sobre Machado de Assis.

Outros aspectos, que certamente fogem nossa análise, aqui e agora, permanecem dispostos na obra para um estudo mais criterioso, e até um olhar diferenciado sobre essa infância não infantilizada que muito tem contribuído para estudos salutares na Literatura brasileira.

\section{Referências}

Almeida, J. F. (2008). Bíblia Sagrada. São Paulo: Sociedade Bíblica do Brasil.

Assis, M. (2003). Várias histórias. São Paulo: Martim

Claret.

Bachelard, G. (1988). A poética do devaneio. São Paulo: Martins Fontes.

Bosi, A. (1999). A máscara e a fenda. In Machado de Assis. O enigma do olhar. São Paulo: Ática.

Gledson, J. (2006). Por um novo Machado de Assis. São

Paulo: Companhia das Letras. 